\title{
Effect of addition of non-functionalized graphene oxide in a commercial epoxy resin used as coating
}

\author{
Jenaro Leocadio Varela Caselis ${ }^{1, *}$, Juana Deisy Santamaría Juárez ${ }^{1}$, José Alberto Galicia Aguilar ${ }^{1}$, \\ María Fernanda Domínguez Alcalá ${ }^{1}$, Efraín Rubio Rosas ${ }^{2}$, José Carlos Mendoza Hernández ${ }^{1}$, Manuel \\ Sánchez Cantú ${ }^{1}$ \\ ${ }^{1}$ Facultad de Ingeniería Química, Benemérita Universidad Autónoma de Puebla, Puebla Mexico \\ ${ }^{2}$ Dirección de Innovación y Transferencia del Conocimiento, Benemérita Universidad Autónoma de Puebla, Puebla Mexico
}

The paper studies the effect of incorporating graphene oxide $(\mathrm{GO})$ without surface functionalization on a commercial epoxy resin. GO was dispersed in a commercial epoxy resin at concentrations of 0 wt. $\%, 0.1$ wt. $\%, 0.5$ wt. $\%, 1$ wt. $\%$, and 3 wt. $\%$. The resultant materials were deposited on carbon steel substrates, followed by the use of a $5 \mathrm{wt} \%$ aqueous $\mathrm{NaCl}$ electrolyte, to evaluate the effectiveness of their anticorrosive coating function. Scanning electron microscopy (SEM) analysis showed that the GO was homogenously dispersed in the polymer matrix, resulting in flat and smooth surfaces. The X-ray diffraction (XRD) results showed that although GO was highly dispersed in the polymer matrix, multilayer graphene was also obtained after curing. The anticorrosive properties were evaluated by electrochemical impedance spectroscopy (EIS) at various exposure periods. Analysis of the prepared samples indicated that the best anticorrosion performance among them was available with the $0.5 \mathrm{wt}$ \% GO coating. The obtained results indicate that GO-polymer matrix composites provide improved corrosion protection properties even after $500 \mathrm{~h}$ exposure to the $\mathrm{NaCl}$ solution.

Keywords: epoxy, graphene oxide, nanocomposite coating, carbon steel, corrosion protection

\section{Introduction}

Epoxy coatings are among the most widely used common industrial polymers due to their outstanding mechanical properties, superior adhesion to substrate, dimensional stability, good chemical resistance, and low cost, as reported by Liu et al. [1] and Wan et al. [2]. However, according to Qi et al. [3] and Wan et al. [4], epoxy coatings are characterized by brittleness and poor resistance to crack propagation. Moreover, they possess hydrophilic hydroxyl groups and free volumes in their structure, making them permeable to aggressive agents such as water, oxygen, and $\mathrm{Cl}^{-}$among others, resulting in increasing corrosion of the metallic substrate over time as demonstrated by Jiang et al. [5] and Ramezanzadeh et al. [6]. Addressing the issue of the susceptibility of epoxy coatings to corrosion, Wang et al. [7] and Alhumade et al. [8] demonstrate that nanocomposite coatings can be consid-

\footnotetext{
*E-mail: genaro.varela@correo.buap.mx
}

ered a promising method for improving corrosion resistance.

According to Ding et al. [9] and Raman et al. [10] graphene, a two-dimensional carbon nanomaterial composed of single-atom-thick sheets of carbon atoms, has been attracting increasing attention in the field of corrosion protection due to its sheet-like structure, antioxidant property, inert nature, hydrophobicity, and barrier properties against aggressive agents. Thus, to benefit from these excellent properties of graphene, the incorporation of graphene nanosheets into the polymer matrix is considered. However, the hydrophobicity of graphene and the aggregation caused by $\pi-\pi$ interactions imply that its dispersability is a major challenge, restricting its application in composite coatings as reported by Wang et al. [11] and Yang et al. [12].

One of the approaches to improve the incorporation of graphene sheets in nanocomposite materials is using graphene in its oxide form graphene oxide (GO); GO possesses functional groups in- 
cluding hydroxyls, epoxides, and carboxyls, due to the presence of which it shows better dispersability in the polymer matrix than graphene. Graphene derivatives based nanocomposites present excellent corrosion protection properties by virtue of their layered structure and very high aspect ratio. For example, in Chang et al. [13] and Singhbabu et al. [14], it is shown that since this graphene derivative is highly hydrophilic, GO does not inhibit the resin-GO composite from undergoing water penetration; however, graphene derivatives based nanocomposites improve the corrosion resistance of organic coatings by elongating the path required to be taken by corroding agents in the coating to reach the metal-coating interface, and by enhancing the barrier properties of the polymer matrix. Kim et al. [15] found that although the GO is intrinsically hydrophilic, it reacts with the epoxy matrix and forms chemicals which can act as hydrophobic agents, and thus enhances the overall hydrophobicity of the composite coating. According to Ramanathan et al. [16], GO contains many oxygen groups, resulting in an enhanced mechanical interlocking with the polymer chains and, consequently, in better adhesion; Zheng et al. [17] reported that the hydroxyl groups, present in large numbers on the surface of GO, react with the epoxy groups on the epoxy monomer under the catalytic enhancement of the polyamine in the curing agent; thus the aliphatic ether is formed, which can strongly bond the GO and epoxy matrix. Moreover, the GO sheets which contain multiple groups of epoxy should be able to make an ideal filler of epoxy resin, according to the observations in Yang et al. [18].

Another alternative to improve the incorporation of GO sheets in nanocomposite materials consists of an additional modification to the surface of the GO (AMGO) with various molecules and functional groups, thus enhancing specific properties. For instance, Pourhashem et al. [19] modified GO sheets with 3-aminopropyl triethoxysilane and 3-glycidyloxypropyl trimethoxysilane to prepare an epoxy-GO coating revealing that silanefunctionalization significantly improved coatings adhesion on the metal substrate increasing the water contact angle on epoxy coatings. Yarahmadi et al. [20] functionalized GO with starch biopolymer. The results suggested that the starch molecules attached to the GO surface efficiently contributed to the crosslinking reactions through GO exfoliation. Meng et al. [21] used polyaniline (PANI) to modify GO by in-situ polymerization, proving that modification using PANI improved GO sheets' dispersion and decreased the formation of initial surface defects, both of which significantly increased the coating's compactness and improved its mechanical properties. Fazli-Shokouhi et al. [22] synthesized epoxy-based PANI-graphene oxide nanosheet (GON) paint coatings. When dip coated on a carbon steel substrate, the epoxy PANIGON coating exhibited improvements by way of significant anticorrosion and antifouling properties, which were attributed to an inhibition process against the corrosive environment.

From the studies mentioned above, it can be concluded that reinforced polymer coatings with GO and AMGO are capable of promising corrosion protection. However, the reinforced polymer coatings with AMGO require additional steps for modifying the GO surface, thus implying the requirement for a more complex and expensive process. The above-mentioned studies also showed that GO functional groups can enhance the composite mechanical interlocking, adhesion, and barrier effect, and strongly bond GO and epoxy matrix. Moreover, GO is well dispersed in epoxy resin. So, using GO without additional surface functionalization for the preparation of anticorrosive nanocomposite coatings can be considered as an interesting alternative due to its simplicity and economy.

In this sense, several studies have reported the mechanical properties of epoxy-GO nanocomposites. Wolk et al. [23] prepared reduced GO-epoxy composites using a combination of a fast heating rate and various drying methods. They found significant changes in the curing behavior and mechanical properties of the composites and that GO acts as flexibilizer. Wang et al. [24] manufactured advanced epoxy nanocomposites by grafting nano-silicon dioxide (nano- $\mathrm{SiO}_{2}$ ) onto $\mathrm{GO}$ through thiol-ene click reaction. Using this method, the interfacial and mechanical properties of GO-epoxy nanocomposites were successfully improved. Bortz et al. [25] improved fatigue life and fracture tough- 
ness in GO-epoxy composites by adding small amounts $(\leq 1 \mathrm{wt} . \%)$ of GO to an epoxy system. However, only a few studies, such as Pourhashem et al. [26], have reported the preparation and anticorrosive performance of epoxy coatings containing GO nanosheets without further functionalization using a commercial epoxy resin.

Therefore, this research primarily aims to enhance the corrosion protective/anticorrosion efficiency of solvent-based epoxy coatings by using a commercial epoxy resin and GO without any surface functionalization. Special emphasis is placed on the GO inclusion percentage in the polymer matrix and its effect on the corrosion performance.

\section{Experimental}

\subsection{Materials}

Samples were prepared by curing commercial epoxy resin DER 331 (epoxide equivalent weight of 182-192 Da), with a commercial epoxy hardener 2767, both received from the Mexican Polymer Corporation. GO was synthesized by a modified Hummers' method [27] using graphite from Sigma-Aldrich. As substrates, cold-rolled carbon steel coupons were used; they were washed with detergent and rinsed with deionized water and acetone, and dried at $60^{\circ} \mathrm{C}$ for $15 \mathrm{~min}$.

\subsection{Preparation of GO-epoxy nanocom- posite coatings}

GO was dispersed in DER 331 at concentrations of 0.1 wt. $\%, 0.5$ wt. $\%, 1$ wt. $\%$, and 3 wt. $\%$, and the samples were labeled as EG0, EG01, EG05, EG1, and EG3, respectively; EG0 was treated as the reference sample. The procedure of the GOepoxy dispersion was as follows: GO powders were dispersed in acetone by ultrasonic treatment for $1 \mathrm{~h}$ at room temperature. Then, GO suspension was mixed with the epoxy resin followed by sonication for $30 \mathrm{~min}$. Next, acetone was removed via evaporation, and finally the stoichiometric amount of hardener 2767 was added to the mixture (the weight ratio of resin to hardener was $1: 1$ ) with mild stirring. The obtained solution was coated onto cold-rolled carbon steel panels using a wire-wound applicator. Then, the panels were stored at room temperature for $24 \mathrm{~h}$ and cured at $120^{\circ} \mathrm{C}$ for $2 \mathrm{~h}$.

\subsection{Characterization}

Scanning electron microscopy (SEM) images of the nanocomposite coatings were obtained by a JEOL JSM-6610LV instrument equipped with an Oxford Instruments energy dispersive X-ray spectroscopy device. The samples were placed on conductive aluminum tape and coated with gold in a sputtering unit (Denton Vacum, DESK v SCD$030)$ before their analysis. The analyses were carried out using a secondary electron detector working in high vacuum mode and at $20 \mathrm{kV}$ of accelerating voltage. X-ray diffraction (XRD) data were collected on a Bruker model diffractometer, D8 Discover, in a Bragg-Brentano geometry using $\mathrm{CuK} \alpha$ radiation $(\lambda=0.15418 \mathrm{~nm})$ and stepscan mode (range: $5-80^{\circ}$ of $2 \theta$, step-time: $0.60 \mathrm{~s}$, step-size: $0.04^{\circ}$ ). Fourier transform infrared spectroscopy (FTIR) was carried out on a Bruker spectrometer model, Vertex 70, in the interval of 500$4,000 \mathrm{~cm}^{-1}$.

\subsection{Electrochemical studies}

The anticorrosive properties were determined by electrochemical impedance spectroscopy (EIS). Coated coupons were immersed into a 5 wt. $\% \mathrm{NaCl}$ solution for $500 \mathrm{~h}$. A three-electrode cell arrangement, with the coated carbon steel substrates as a working electrode, a graphite bar as a counter electrode, and a saturated calomel electrode as the reference electrode, was used. AC impedance measurements were conducted on open circuit potential using a Gamry, Reference 600 potentiostat/galvanostat/ZRA over a frequency range of $100 \mathrm{kHz}-10 \mathrm{mHz}$, and the amplitude of sinusoidal voltage was $10 \mathrm{mV}$. Interpretation of the impedance data was performed using the Gamry Instruments Echem Analyst fitting program, version 6.25.

\section{Results and discussion}

\subsection{Coating's microstructure}

GO dispersion in DER 331 matrix was first investigated by SEM (Figure 1). The micrographs re- 


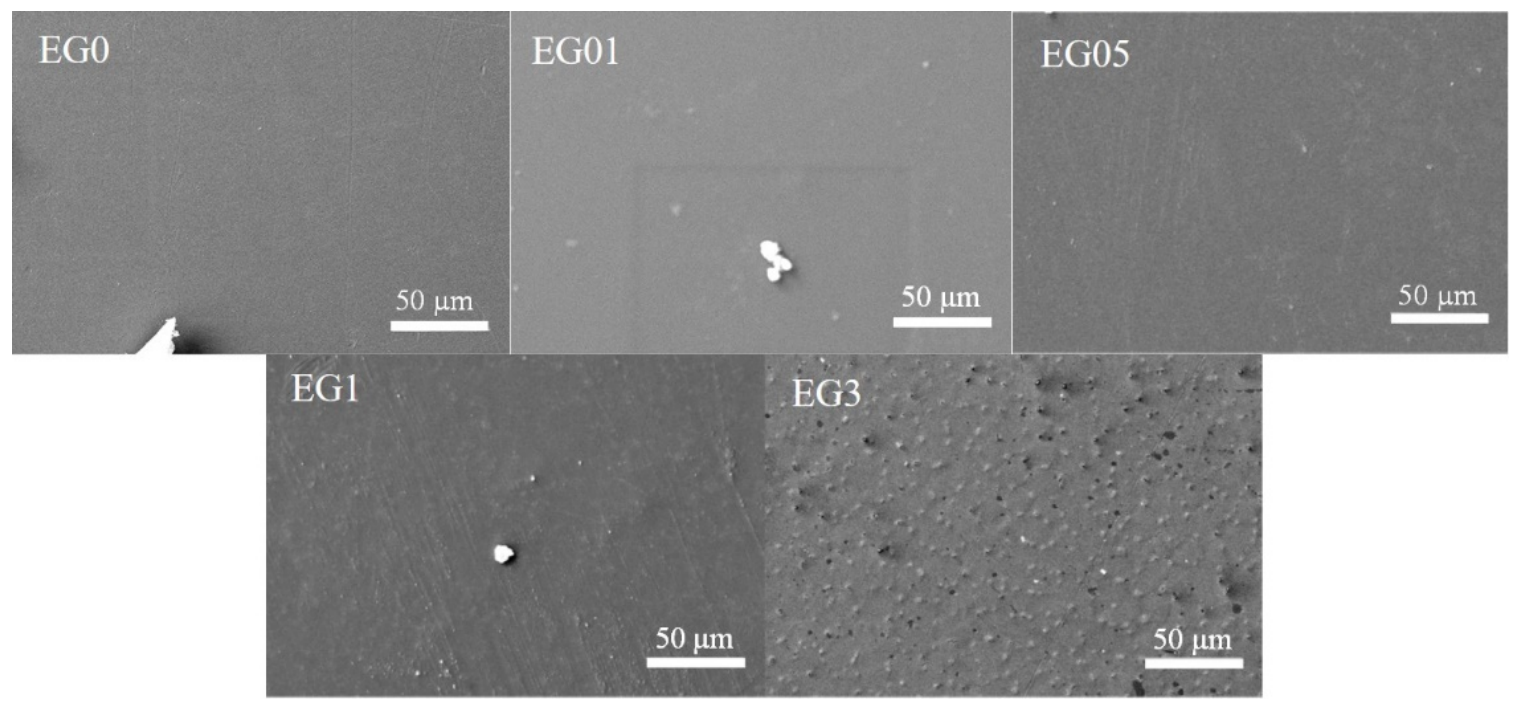

Fig. 1. SEM micrograph coatings' surface of the EG0, EG01, EG05, EG1, and EG3 samples. SEM, scanning electron microscopy

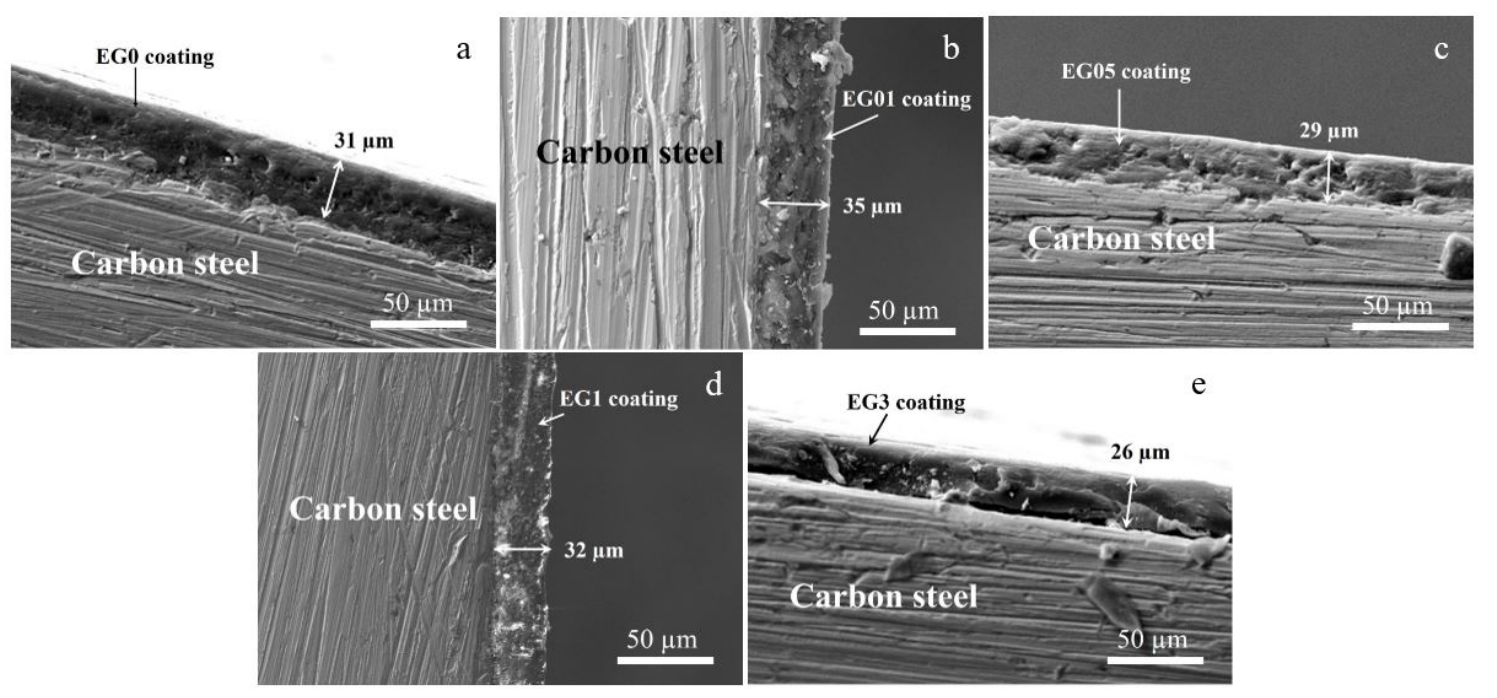

Fig. 2. SEM micrographs of the surface coatings: (A) EG0, (B) EG01, (C) EG05, (D) EG1, and (E) EG3. SEM, scanning electron microscopy

vealed that the EG0, EG01, and EG05 epoxy coatings exhibited smooth and homogeneous surfaces without cracks or discontinuities. Nevertheless, the surface became rougher when the GO increased, as can be seen in EG1 and EG3 (Figure 1). Moreover, GO clusters were clearly identified in EG3 indicating that an incorporation and dispersion limit is achieved, then when the content of GO increases, good dispersion and exfoliation of GO is not obtained in the samples.
Figure 2 shows the coatings' cross-section, where an adhesion in the coating-metal interface can be observed for all samples, reaching the best results each with the EG0, EG01, EG05, and EG1 samples. The average of the measured coatings' thicknesses was found to be in the 26-35 $\mu \mathrm{m}$ range. It would be relevant to mention in this context that a plausible explanation for the poor coating-metal adhesion disclosed by EG3 is the GO cluster formation (Figure 1E). 

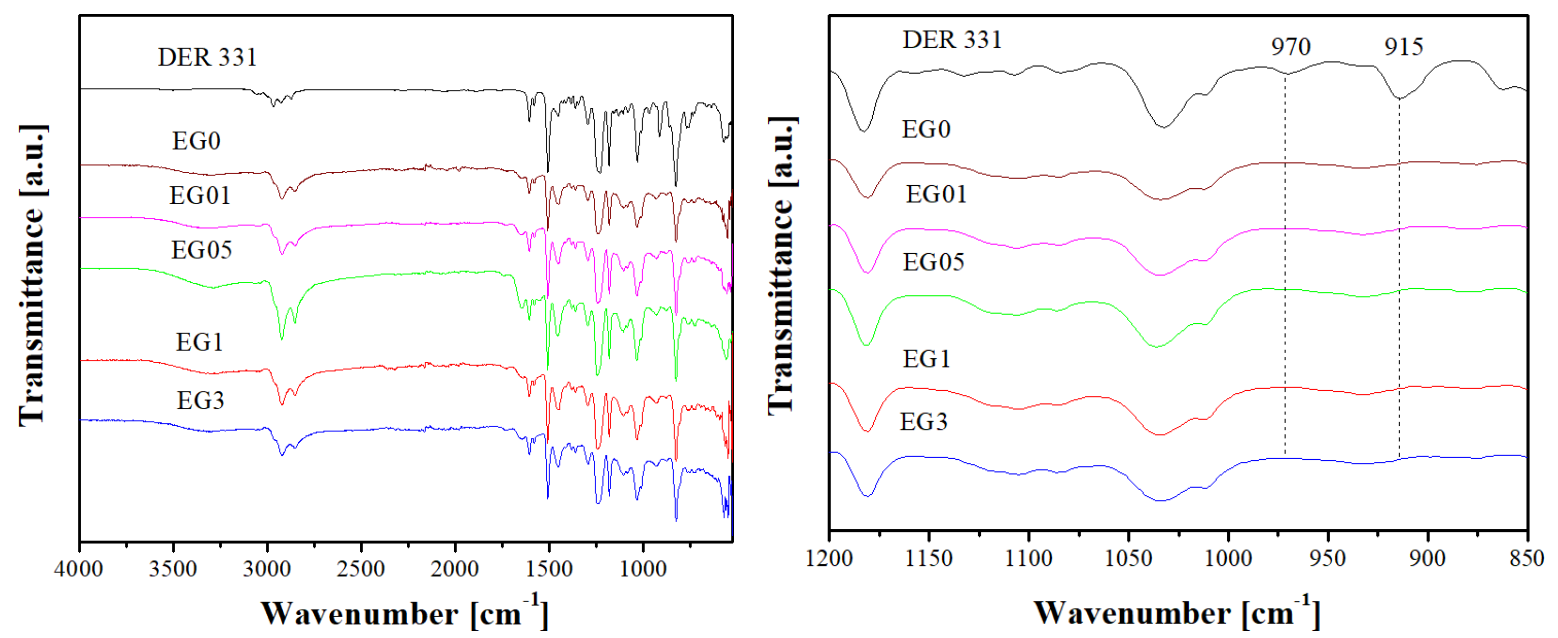

Fig. 3. FTIR spectra of the EG0, EG01, EG05, EG1, and EG3 samples; the epoxy absorption peaks are indicated in the spectra. FTIR, Fourier transform infrared spectroscopy
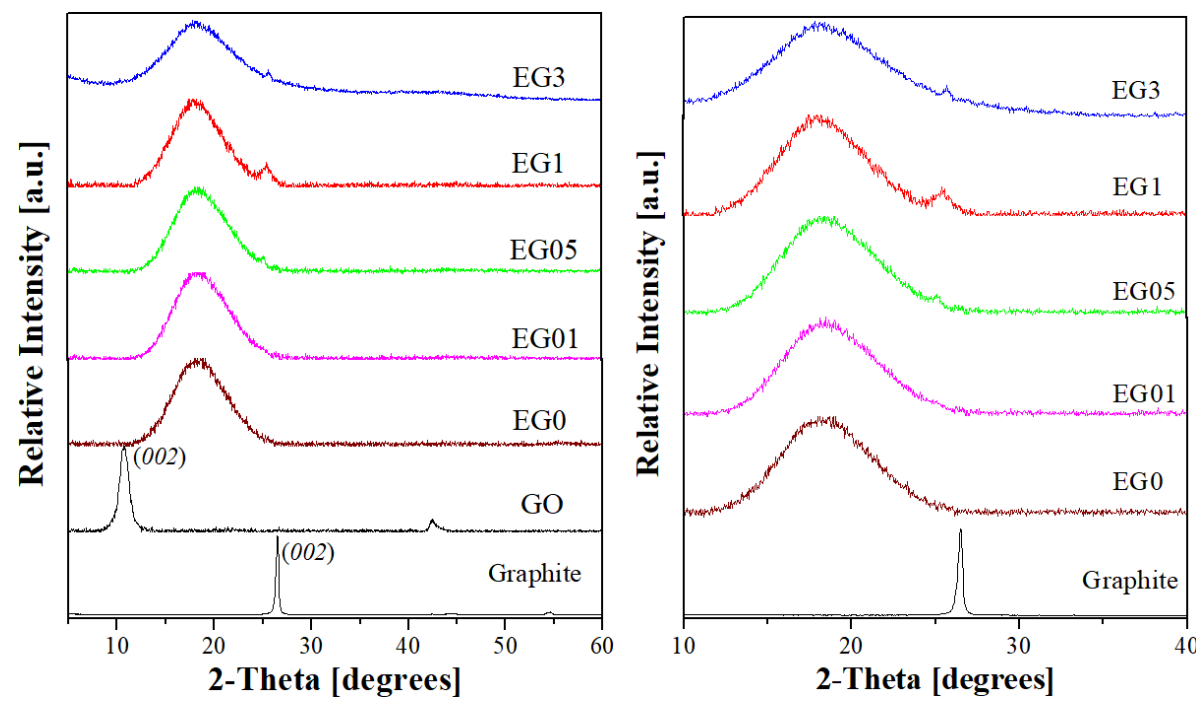

Fig. 4. XRD diffractograms of the graphite, GO, EG0, EG01, EG05, EG1, and EG3 samples. GO, Graphene oxide; XRD, X-ray diffraction

The synthesized samples were analyzed by FTIR spectroscopy (Figure 3) to monitor the curing reaction of epoxy resin by considering the absorbance decrease of the oxirane group band located in the $970-914 \mathrm{~cm}^{-1}$ region. After curing, this band disappears in the coatings' samples, indicating a good curing reaction as reported by Grundmeier et al. [28] and Zheng et al. [29].

GO dispersion in epoxy resin was also studied by the XRD technique to determine the structural transformation in GO, if any, after its incorpora- tion in the resin matrix (Figure 4). Pristine graphite and GO were also included for comparison. The characteristic reflections of pristine graphite were identified at 26.5, 44.5, and 54.5 of $2 \theta$ degrees (PDF \# 41-1487). The interlayer spacing was calculated from the (002) plane corresponding value of $0.33 \mathrm{~nm}$. On the other hand, the XRD pattern of GO showed a characteristic reflection at $2 \theta=$ $10.7^{\circ}$, which corresponded to an interlayer spacing of about $0.83 \mathrm{~nm}$. The interlayer spacing observed in the case of GO is larger than that of graphite 
$(0.33 \mathrm{~nm})$, and the larger interlayer spacing of GO is attributable to the "decoration" given to it by oxygen-containing groups, which expand the interlayer distance, as indicated in the researches of Liao et al. [30] and Pei and Cheng [31].

All samples exhibited a broad signal centered at $2 \theta=18.40$, which is related to the amorphous structure of cured epoxy resin. It is important to note that GO characteristic reflections were not detected, which is indicative of its good dispersion in the resin matrix.

However, the XRD spectra of samples EG05, EG1, and EG3 also showed small reflections centered at $25.07^{\circ}, 25.39^{\circ}$, and $25.67^{\circ}$, respectively, which were attributed to multilayer graphene, which is formed during the thermal curing process [32]. These results showed that after the curing treatment, part of the GO structure transformed into multilayer graphene, achieving interlayer spacing values of $0.355 \mathrm{~nm}, 0.351 \mathrm{~nm}$, and $0.347 \mathrm{~nm}$ (corresponding to EG05, EG1, and EG3, respectively). Besides, a broadening effect was also noticed with GO increase (which is more evident in EG1), indicating that graphene stacking is not well ordered [33]. By the Scherrer equation $-\mathrm{L}_{(200)}=$ $\mathrm{k} \lambda / \beta \cos \theta$, where $\mathrm{k}$ is a dimensionless shape factor with a value of $0.9, \lambda$ is the $\mathrm{X}$-ray wavelength, $\beta$ is the line broadening determined by the full width at half maximum (FWHM), and $\theta$ is Bragg's angle - GO thickness was determined, obtaining a value of $7.1 \mathrm{~nm}$. In this sense, if $d_{(002)}$ is considered as an individual GO layer, a multilayered graphene consisting of $\sim 9$ (8.54) graphene layers can be assumed.

\subsection{Coatings' anticorrosive properties}

Figure 5 shows the electrical equivalent circuit that models the electrochemical behavior of the coated steel panels exposed to $5 \mathrm{wt} \% \mathrm{NaCl}$ solution. The equivalent circle consists of $\mathrm{R}_{E}$, constant phase element $(\mathrm{CPE})_{c}, \mathrm{R}_{C}, \mathrm{CPE}_{d l}$, and $\mathrm{R}_{C T}$, which are solution resistance, coating $\mathrm{CPE}$, coating pore resistance, double layer constant phase, and charge transfer resistance, respectively. The presented model employs CPEs instead of capacitors; CPE represents the deviation from ideal capacitive behavior and is used in the equivalent circuit to minimize the systematical error and obtain more precious fitting results. The CPE is associated with an exponent $(0 \leq N \leq 1)$ which indicates the deviation from an ideal dielectric behavior; if $N=1$, it represents an ideal capacitor behavior and if $N$ $=0$, it behaves as an ideal resistor, as reported by Mondal et al. [34].

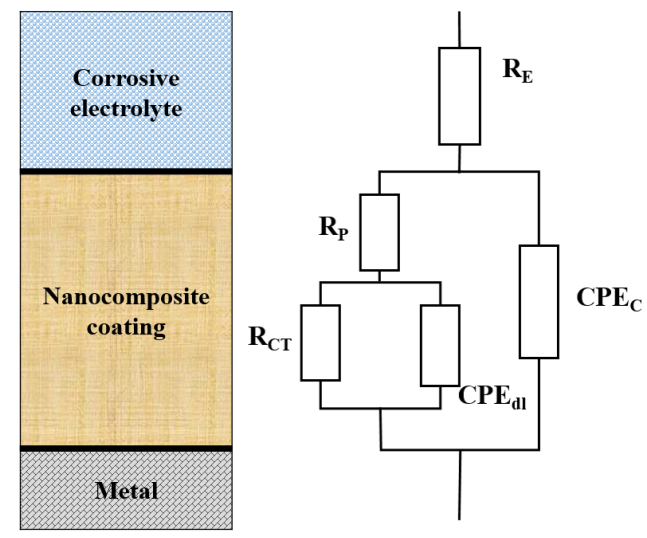

Fig. 5. EEC for the studied coating systems. CPE, Constant phase element

EIS measurement is used to evaluate the corrosion protection performance of nanocomposite coatings with different GO wt.\%. The Bode and Nyquist plots of samples after immersion in $5 \mathrm{wt} . \%$ $\mathrm{NaCl}$ solution for $0 \mathrm{~h}, 150 \mathrm{~h}, 300 \mathrm{~h}$, and $500 \mathrm{~h}$ are presented in Figures 6 and 7.

Figure 6 shows that the impedance value of nanocomposite coatings significantly depends on GO wt.\%. The impedance value of nanocomposite coatings decreases in the order of $0.5 \mathrm{wt} . \%$ $\mathrm{GO}>0.1$ wt. $\% \mathrm{GO}>0.0$ wt. $\% \mathrm{GO}>1$ wt. $\%$ $\mathrm{GO}>3$ wt. $\%$ GO during immersion time. Furthermore, the impedance values of coatings decrease by increasing immersion time.

The Bode plot for EG0, EG01, and EG05 is a straight line with a negative slope $(-1)$ in the first times, revealing that the coating behaved as a perfect capacitor (Figure 6A), showing extremely high resistance of the pore $\left(\mathrm{R}_{p}\right)$ for nanocomposite coatings. The impedance for EG1 and EG3 were lower and the little plateau observed in the Bode plot confirmed that these coatings had begun water absorption. 

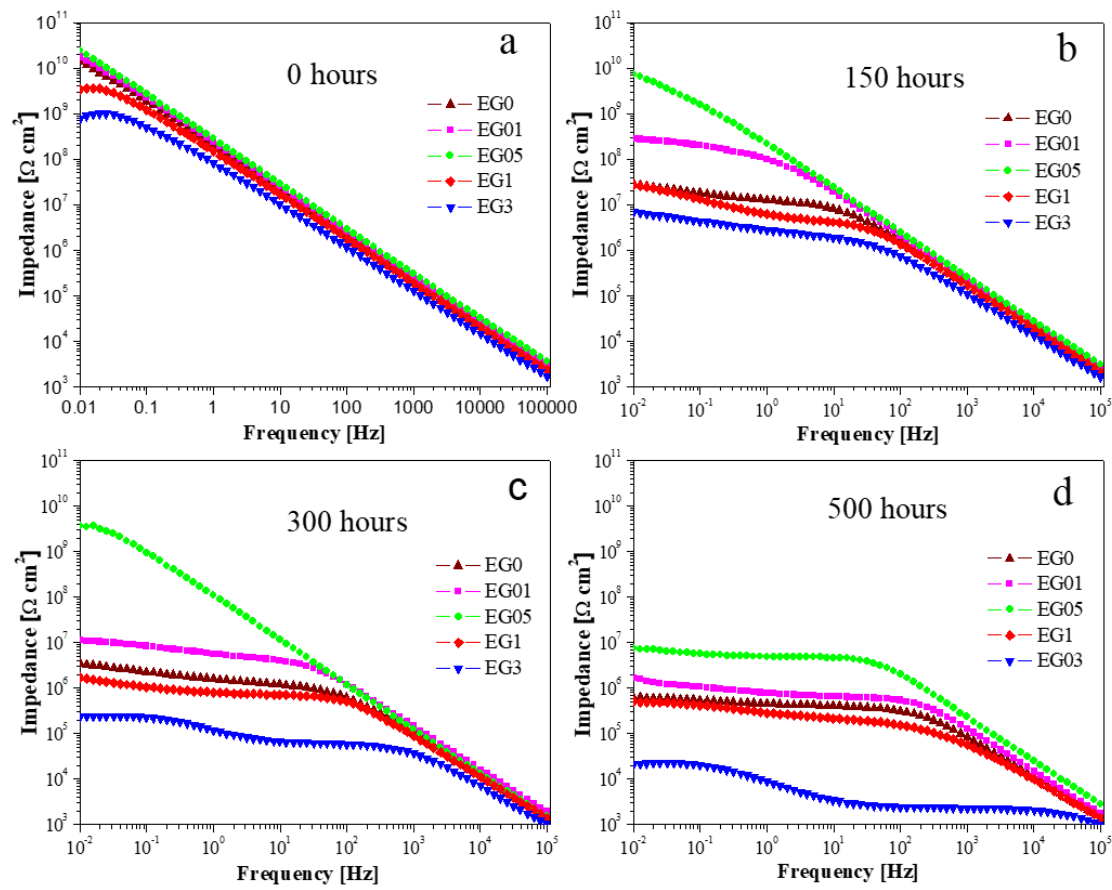

Fig. 6. Bode diagrams of the EG0, EG01, EG05, EG1, and EG3 samples immersed in 5 wt.\% $\mathrm{NaCl}$ solution. (A) Initial immersion; (B) After 150 h; (C) After 300 h; (D) After 500 h
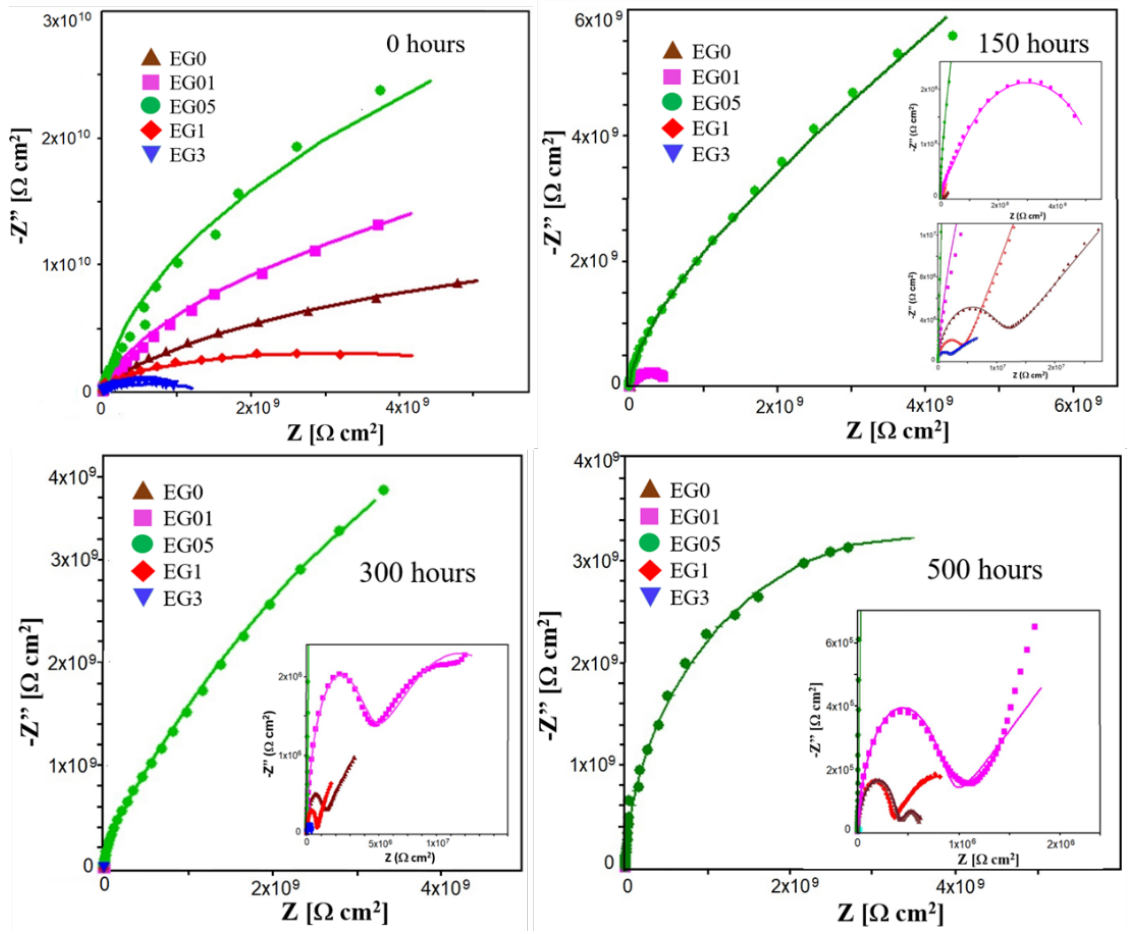

Fig. 7. Nyquist diagrams of the EG0, EG01, EG05, EG1, and EG3 samples immersed in 5 wt.\% NaCl solution: (A) Initial immersion; (B) After 150 h; (C) After 300 h; (D) After 500 h; marker points and solid lines show the experimental and fitted data, respectively 
Table 1. The electrochemical parameters extracted from EIS data for nanocomposite epoxy coatings containing 0 wt. $\%, 0.1$ wt. $\%, 0.5$ wt. $\%, 1$ wt. $\%$, and $3 \mathrm{wt} . \% \mathrm{GO}$ after immersion in $5 \mathrm{wt} . \% \mathrm{NaCl}$ solution for different durations

\begin{tabular}{|c|c|c|c|c|c|c|c|c|}
\hline \multirow[t]{2}{*}{ Sample } & \multirow{2}{*}{$\begin{array}{l}\text { time } \\
\text { (hours) }\end{array}$} & \multicolumn{2}{|c|}{$\mathrm{CPE}_{C}$} & \multirow{2}{*}{$\begin{array}{l}\mathrm{R}_{P} \\
\left(\Omega \cdot \mathrm{cm}^{2}\right)\end{array}$} & \multicolumn{2}{|c|}{$\mathrm{CPE}_{d l}$} & \multirow{2}{*}{$\begin{array}{l}\mathrm{R}_{C T} \\
\left(\Omega \cdot \mathrm{cm}^{2}\right)\end{array}$} & \multirow[t]{2}{*}{$x^{2}$} \\
\hline & & $\begin{array}{l}\mathrm{Y}_{0} \\
\left(\Omega^{-1} \cdot \mathrm{cm}^{-2} \cdot \mathrm{s}^{n}\right)\end{array}$ & $\mathrm{n}$ & & $\begin{array}{l}\mathrm{Y}_{0} \\
\left(\Omega^{-1} \cdot \mathrm{cm}^{-2} \cdot \mathrm{s}^{n}\right)\end{array}$ & $\mathrm{n}$ & & \\
\hline \multirow[t]{4}{*}{ EG0 } & 0 & $8.70 \mathrm{E}-10$ & $9.77 \mathrm{E}-01$ & $4.89 \mathrm{E}+10$ & $7.11 \mathrm{E}-10$ & $9.52 \mathrm{E}-01$ & $1.45 \mathrm{E}+10$ & $4.64 \mathrm{E}-04$ \\
\hline & 150 & $2.32 \mathrm{E}-09$ & $9.56 \mathrm{E}-01$ & $9.80 \mathrm{E}+06$ & $1.37 \mathrm{E}-07$ & $4.00 \mathrm{E}-01$ & $6.07 \mathrm{E}+08$ & $2.42 \mathrm{E}-04$ \\
\hline & 300 & $1.96 \mathrm{E}-09$ & $9.15 \mathrm{E}-01$ & $9.50 \mathrm{E}+06$ & $7.44 \mathrm{E}-07$ & $2.89 \mathrm{E}-01$ & $2.36 \mathrm{E}+07$ & $3.96 \mathrm{E}-04$ \\
\hline & 500 & $5.79 \mathrm{E}-09$ & $8.71 \mathrm{E}-01$ & 321000 & $4.67 \mathrm{E}-06$ & $5.61 \mathrm{E}-01$ & $8.71 \mathrm{E}+05$ & $2.59 \mathrm{E}-03$ \\
\hline \multirow[t]{4}{*}{ EG01 } & 0 & $6.96 \mathrm{E}-10$ & $9.66 \mathrm{E}-01$ & $5.45 \mathrm{E}+10$ & $2.92 \mathrm{E}-10$ & $6.00 \mathrm{E}-01$ & $1.49 \mathrm{E}+12$ & $2.39 \mathrm{E}-03$ \\
\hline & 150 & $1.80 \mathrm{E}-09$ & $9.34 \mathrm{E}-01$ & $8.24 \mathrm{E}+07$ & $5.53 \mathrm{E}-09$ & $8.40 \mathrm{E}-01$ & $4.64 \mathrm{E}+08$ & $4.40 \mathrm{E}-03$ \\
\hline & 300 & $2.38 \mathrm{E}-09$ & $9.51 \mathrm{E}-01$ & $3.90 \mathrm{E}+07$ & $1.77 \mathrm{E}-07$ & $3.97 \mathrm{E}-01$ & $1.12 \mathrm{E}+07$ & $2.82 \mathrm{E}-04$ \\
\hline & 500 & $4.46 \mathrm{E}-09$ & $9.38 \mathrm{E}-01$ & 431000 & $1.82 \mathrm{E}-06$ & $2.63 \mathrm{E}-01$ & $5.58 \mathrm{E}+08$ & $9.06 \mathrm{E}-04$ \\
\hline \multirow[t]{4}{*}{ EG05 } & 0 & $7.97 \mathrm{E}-10$ & $9.82 \mathrm{E}-01$ & $9.60 \mathrm{E}+10$ & $1.72 \mathrm{E}-09$ & $8.23 \mathrm{E}-01$ & $5.30 \mathrm{E}+09$ & $6.68 \mathrm{E}-04$ \\
\hline & 150 & $9.28 \mathrm{E}-10$ & $9.77 \mathrm{E}-01$ & $8.73 \mathrm{E}+09$ & $3.53 \mathrm{E}-10$ & $4.35 \mathrm{E}-01$ & $1.38 \mathrm{E}+12$ & $3.56 \mathrm{E}-04$ \\
\hline & 300 & $7.13 \mathrm{E}-10$ & $9.69 \mathrm{E}-01$ & $7.26 \mathrm{E}+09$ & $8.56 \mathrm{E}-10$ & $6.19 \mathrm{E}-01$ & $1.27 \mathrm{E}+10$ & $4.45 \mathrm{E}-04$ \\
\hline & 500 & $9.13 \mathrm{E}-10$ & $9.59 \mathrm{E}-01$ & $4.70 \mathrm{E}+09$ & $2.66 \mathrm{E}-11$ & $1.80 \mathrm{E}-01$ & $6.21 \mathrm{E}+07$ & $1.08 \mathrm{E}-02$ \\
\hline \multirow[t]{4}{*}{ EG1 } & 0 & $1.06 \mathrm{E}-09$ & $9.70 \mathrm{E}-01$ & $5.29 \mathrm{E}+09$ & $1.34 \mathrm{E}-13$ & $9.59 \mathrm{E}-01$ & $6.32 \mathrm{E}+09$ & $5.01 \mathrm{E}-03$ \\
\hline & 150 & $2.97 \mathrm{E}-09$ & $8.99 \mathrm{E}-01$ & $3.94 \mathrm{E}+06$ & $1.62 \mathrm{E}-07$ & $6.20 \mathrm{E}-01$ & $2.96 \mathrm{E}+10$ & $8.81 \mathrm{E}-02$ \\
\hline & 300 & $3.14 \mathrm{E}-09$ & $8.96 \mathrm{E}-01$ & $1.54 \mathrm{E}+07$ & $2.36 \mathrm{E}-06$ & $4.46 \mathrm{E}-01$ & $5.84 \mathrm{E}+06$ & $7.93 \mathrm{E}-04$ \\
\hline & 500 & $7.05 \mathrm{E}-09$ & $9.57 \mathrm{E}-01$ & 138000 & $3.62 \mathrm{E}-06$ & $4.12 \mathrm{E}-01$ & $4.11 \mathrm{E}+06$ & $3.24 \mathrm{E}-04$ \\
\hline \multirow[t]{4}{*}{ EG3 } & 0 & $2.41 \mathrm{E}-09$ & $8.13 \mathrm{E}-01$ & $3.16 \mathrm{E}+09$ & $2.42 \mathrm{E}-09$ & $9.23 \mathrm{E}-01$ & $1.30 \mathrm{E}+09$ & $2.31 \mathrm{E}-02$ \\
\hline & 150 & $4.18 \mathrm{E}-09$ & $9.19 \mathrm{E}-01$ & $1.32 \mathrm{E}+06$ & $3.35 \mathrm{E}-07$ & $3.00 \mathrm{E}-01$ & $3.38 \mathrm{E}+07$ & $4.36 \mathrm{E}-04$ \\
\hline & 300 & $1.50 \mathrm{E}-08$ & $8.80 \mathrm{E}-01$ & 22330 & $5.37 \mathrm{E}-06$ & $7.99 \mathrm{E}-01$ & $1.89 \mathrm{E}+05$ & $1.56 \mathrm{E}-03$ \\
\hline & 500 & $2.48 \mathrm{E}-08$ & $8.54 \mathrm{E}-01$ & 2270 & $2.81 \mathrm{E}-05$ & $7.46 \mathrm{E}-01$ & $2.22 \mathrm{E}+04$ & $1.91 \mathrm{E}-03$ \\
\hline
\end{tabular}

CPE, Constant phase element; EIS, Electrochemical impedance spectroscopy; GO, Graphene oxide

After $150 \mathrm{~h}$ of immersion, it was observed that the impedance value was lower than its early state. For instance, the EG05 impedance value decreased to $7.1 \mathrm{G} \Omega \cdot \mathrm{cm}^{-2}$ but it maintained a linear relationship with frequency and the slope did not change, suggesting water absorption. In the same way, the impedance of neat epoxy (EG0), EG01, and EG1 coated samples also decreased to $28.2 \mathrm{M} \Omega \cdot \mathrm{cm}^{-2}$, $27.5 \mathrm{M} \Omega \cdot \mathrm{cm}^{-2}$, and $26.6 \mathrm{M} \Omega \cdot \mathrm{cm}^{-2}$, respectively. As revealed by the horizontal intersections of the graph with the impedance modulus axis in the Bode plot (Figure 6B), this behavior is indicative of the electrolyte's penetration of the coatings. It is worth mentioning that sample EG3 registered an impedance value of $6.9 \mathrm{M} \Omega \cdot \mathrm{cm}^{-2}$, which was the lowest among the samples; this observation is in good agreement with the XRD and SEM analysis, which revealed cluster formation, structure distortion, and lower substrate-coating adhesion.
After $300 \mathrm{~h}$ of immersion, sample EG05 provided a better barrier protection $\left(4.95 \mathrm{G} \Omega \cdot \mathrm{cm}^{-2}\right.$ ) than the others. The impedance value of sample EG3 was the lowest; this was signaled by a more complex Bode plot, which exhibited two time constants, indicating the initiation of metallic substrate corrosion. After $500 \mathrm{~h}$ of immersion, the Bode plot for sample EG05 showed the highest impedance $\left(3.71 \mathrm{G} \Omega \cdot \mathrm{cm}^{-2}\right)$, while there was a decrease in the protective properties of the EG01, EG0, EG1, and EG3 samples, meaning that water had diffused into the coating.

\subsubsection{Variations of corrosion electrochemical parameters}

Coating resistance $\left(\mathrm{R}_{p}\right)$ is related to the barrier property of coating, and it was thus used to evaluate the protective performance of the coatings. The coating capacitance $\left(\mathrm{C}_{c}\right)$ is closely related to the 

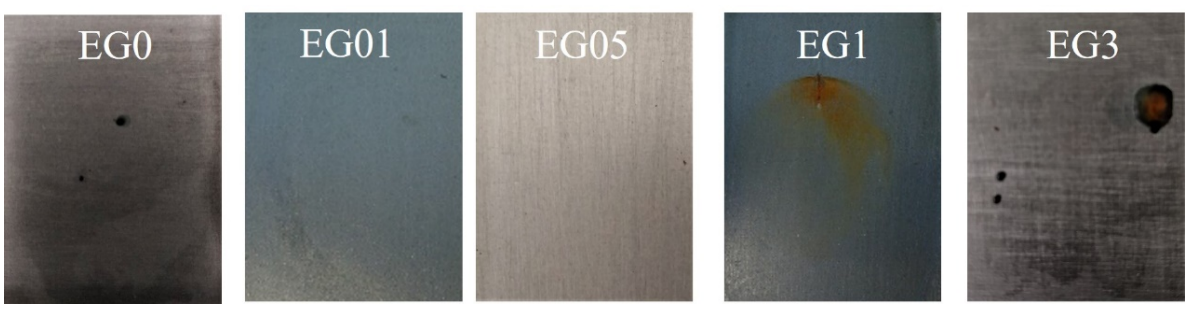

Fig. 8. Photographs showing the surfaces of coated steel panels after the boundary corrosion test; EG0, EG01, EG05, EG1, and EG3 in 5\% $\mathrm{NaCl}$ solution

diffusion behavior of the electrolyte in the coating, which reflects the barrier properties of the coating [35]. When the electrolyte penetrates the coating, its dielectric constant changes, resulting in a $\mathrm{C}_{c}$ variation.

As can be seen from Table 1 , the $\mathrm{R}_{p}$ and $\mathrm{R}_{C T}$ of all coatings decreased gradually until the end of the test. During the exposure time, the $\mathrm{R}_{p}$ and $\mathrm{R}_{C T}$ values of sample EG05 decreased slowly; also, these values were significantly higher than those of the other samples, including the reference sample EG0, throughout the entire investigated time. This behavior can be explained in terms of the micropores' filling by GO, leading to significant enhancement of the barrier properties. When the corrosive electrolyte reaches the coating-metal interface, electrochemical reactions, including oxidation of active sites on the metal surface and reduction of solution species $\left(\mathrm{O}_{2}\right.$ and $\mathrm{H}^{+}$ions $)$, take place, leading to the formation and dissolution of corrosion products affecting the coating's electrochemical parameters.

The overall loss of coating resistance for sample EG3 is much sharper (6 and 5 orders of magnitude) than the other samples. These findings indicate that delamination occurred in sample EG3, which is consistent with the visual examination of the exposed panels (Figure 8).

Table 1 shows that the EG0, EG01, and EG1 samples' $\mathrm{CPE}_{C}$ ascended slowly in the initial stage of exposure and then declined to a stable amount, indicating that the homogeneity of the coatings decreased along with the water uptake process, which continued until the coatings were saturated with water. Overall, the highest coating capacitance values were obtained for sample EG3, where the amount of GO was 3 wt.\%, suggesting a higher water uptake; this is due to functional groups in GO making it hydrophilic; and as a result of increasing the GO, more electrolytes permeate into the coating [36]. Moreover, GO aggregation occurs when the amount of GO in nanocomposite coatings (ascertained based on SEM observations) is increased, leading to decrease of GO aspect ratio and therefore acceleration of the corrosion phenomenon [37].

This is consistent with the results from visual examination of the exposed panels (Figure 8), where sample EG03 showed evident corrosion spots and delamination. In turn, the lowest coating capacitance values were obtained for sample EG05, indicating a lower water absorption than in the case of epoxy coating.

All of these observations demonstrate that GO wt.\%, and therefore GO distribution in the polymer matrix, have an important influence on coating protective performance. According to SEM results, GO nanosheets tend to agglomerate in the polymer matrix by increasing GO wt. $\%$ to $>0.5$ wt. $\%$, and this agglomeration is attributed to their high specific surface area [38]. Also, nanocomposites containing $0.5 \mathrm{wt} . \%$ GO have the best GO distribution in the polymer matrix.

\section{Conclusions}

SEM analysis proves that uniform epoxy-GO coatings were obtained, and that there was a homogenous dispersion of GO in the polymer matrix. Through XRD analysis, it was also verified that GO was highly dispersed in epoxy resin. However, multilayer graphene was also obtained after the curing process. Electrochemical impedance measure- 
ments, at various exposure periods, indicated that the EG05 coating showed better anticorrosive properties than the other coatings in $5 \mathrm{wt} . \% \mathrm{NaCl}$ solution. EIS results were in good agreement with the visual evaluation test, demonstrating that the EG05 coating had a better corrosion resistance among the prepared samples. This study shows that the addition of GO synthesized by Hummers' modified method improves the anticorrosive properties of a commercial epoxy resin DER 331.

\section{References}

[1] Liu S, Yan HQ, Fang ZP, Wang H. Effect of graphene nanosheets on morphology, thermal stability and flame retardancy of epoxy resin. Compos Sci Technol. 2014;90:40-7

[2] Wan YJ, Gong LX, Tang LC, Wu LB, Jiang JX. Mechanical properties of epoxy composites filled with silanefunctionalized graphene oxide. Compos A Appl Sci Manuf. 2014;64:79-89.

[3] Qi B, Lu SR, Xiao XE, Pan LL, Tan FZ, Yu JH. Enhanced thermal and mechanical properties of epoxy composites by mixing thermotropic liquid crystalline epoxy grafted graphene oxide. Expr Polym Lett. 2014;8(7):467-79.

[4] Wan YJ, Tang LC, Gong LX, Yan D, Li YB, Wu LB, et al. Grafting of epoxy chains onto graphene oxide for epoxy composites with improved mechanical and thermal properties. Carbon. 2014;69:467-80.

[5] Jiang MY, Wu LK, Hu JM, Zhang JQ. Silaneincorporated epoxy coatings on aluminum alloy (AA2024). Part 1: Improved corrosion performance. Corros Sci. 2015;92:118-26.

[6] Ramezanzadeh B, Ghasemi E, Mahdavian M, Changizi E, Moghadam MM. Covalently-grafted graphene oxide nanosheets to improve barrier and corrosion protection properties of polyurethane coatings. Carbon. 2015;93:555-73.

[7] Wang X, Xing W, Song L, Yang H, Hu Y, Yeoh GH. Fabrication and characterization of graphene-reinforced waterborne polyurethane nanocomposite coatings by the sol-gel method. Surf Coat Technol. 2012;206(23):477884.

[8] Alhumade H, Yu A, Elkamel A, Simon L, Abdala A. Enhanced protective properties and UV stability of epoxy/graphene nanocomposite coating on stainless steel. Expr Polym Lett. 2016;10(12):1034-46.

[9] Ding R, Li W, Wang X, Gui T, Li B, Han P, et al. A brief review of corrosion protective films and coatings based on graphene and graphene oxide. J Alloys Compds. 2018;764:1039-55.

[10] Raman RKS, Banerjee PC, Lobo DE, Gullapalli H, Sumandasa M, Kumar A, et al. Protecting copper from electrochemical degradation by graphene coating. Carbon. 2012;50(11):4040-5.
[11] Wang X, Xing W, Zhang P, Song L, Yang H, Hu Y. Covalent functionalization of graphene with organosilane and its use as a reinforcement in epoxy composites. Compos Sci Technol. 2012;72(6):737-43.

[12] Yang SY, Lin WN, Huang YL, Tien HW, Wang JY, Ma $\mathrm{CC}$, et al. Synergetic effects of graphene platelets and carbon nanotubes on the mechanical and thermal properties of epoxy composites. Carbon. 2011;49(3):793-803.

[13] Chang K-C, Hsu M-H, Lu H-I, Lai M-C, Liu P-J, Hsu C-H, et al. Room-temperature cured hydrophobic epoxy/graphene composites as corrosion inhibitor for cold-rolled steel. Carbon. 2014;66:144-53.

[14] Singhbabu YN, Sivakumar B, Singh JK, Bapari H, Pramanick AK, Sahu RK. Efficient anti-corrosive coating of cold-rolled steel in a seawater environment using an oilbased graphene oxide ink. Nanoscale. 2015;7(17):803547.

[15] Kim H, Abdala AA, Macosko CW. Graphene/polymer nanocomposites. Macromolecules. 2010;43(16):651530.

[16] Ramanathan T, Abdala AA, Stankovich S, Dikin DA, Herrera-Alonso M, Piner RD, et al. Functionalized graphene sheets for polymer nanocomposites. Nat Nanotechnol. 2008;3(6):327-31.

[17] Zheng W, Chen WG, Zhao Q, Ren SX, Fu YQ. Interfacial structures and mechanisms for strengthening and enhanced conductivity of graphene/epoxy nanocomposites. Polymer. 2019;163:171-7.

[18] Yang H, Shan C, Li F, Zhang Q, Han D, Niu L. Convenient preparation of tunably loaded chemically converted graphene oxide/epoxy resin nanocomposites from graphene oxide sheets through two-phase extraction. J Mater Chem. 2009;19(46):8856-60.

[19] Pourhashem S, Vaezi MR, Rashidi A, Bagherzadeh MR. Distinctive roles of silane coupling agents on the corrosion inhibition performance of graphene oxide in epoxy coatings. Prog Org Coat. 2017;111:47-56.

[20] Yarahmadi E, Didehban K, Sari MG, Saeb MR, Shabanian M, Aryanasab F, et al. Development and curing potential of epoxy/starch-functionalized graphene oxide nanocomposite coatings. Prog Org Coat. 2018;119:194202.

[21] Meng F, Zhang T, Liu L, Cui Y, Wang F. Failure behaviour of an epoxy coating with polyaniline modified graphene oxide under marine alternating hydrostatic pressure. Surf Coat Technol. 2019;361:188-95.

[22] Fazli-Shokouhi S, Nasirpouri F, Khatamian $M$. Polyaniline-modified graphene oxide nanocomposites in epoxy coatings for enhancing the anticorrosion and antifouling properties. J Coat Technol Res. 2019;16(4):983-97.

[23] Wolk A, Rosenthal M, Weiss J, Voigt M, Wesendahl JN, Hartmann M, et al. Graphene oxide as flexibilizer for epoxy amine resins. Prog Org Coat. 2018;122:280-9.

[24] Wang M, Ma L, Shi L, Feng P, Wang X, Zhu Y, et al. Chemical grafting of nano-SiO2 onto graphene oxide via thiol-ene click chemistry and its effect on the inter- 
facial and mechanical properties of GO/epoxy composites. Compos Sci Technol. 2019;182:107751; https : // doi.org/10.1016/j.compscitech. 2019.107751

[25] Bortz DR, Heras EG, Martin-Gullon I. Impressive fatigue life and fracture toughness improvements in graphene oxide/epoxy composites. Macromolecules. 2012;45(1):238-45.

[26] Pourhashem S, Vaezi MR, Rashidi A, Bagherzadeh MR. Exploring corrosion protection properties of solvent based epoxy-graphene oxide nanocomposite coatings on mild steel. Corros Sci. 2017;115:78-92.

[27] Zaaba NI, Foo KL, Hashim U, Tan SJ, Liu WW, Voon $\mathrm{CH}$. Synthesis of graphene oxide using modified hummers method: Solvent influence. Adv Mater Process Technol Conf. 2017;184:469-77.

[28] Grundmeier G, Schmidt W, Stratmann MJ. Corrosion protection by organic coatings: Electrochemical mechanism and novel methods of investigation. Electrochim Acta. 2000;45(15-16):2515-33.

[29] Zheng T, Xi H, Wang Z, Zhang X, Wang Y, Qiao Y, et al. The curing kinetics and mechanical properties of epoxy resin composites reinforced by PEEK microparticles. Polym Test. 2020;91:106781; https : //doi .org/ 10.1016/j .polymertesting . 2020. 106781

[30] Liao KH, Mittal A, Bose S, Leighton C, Mkhoyan KA, Macosko CW. Aqueous only route toward graphene from graphite oxide. ACS Nano. 2011;5(2):1253-8.
[31] Pei S, Cheng HM. The reduction of graphene oxide. Carbon. 2012;50(9):3210-28.

[32] Umar MI, Yap CC, Awang R, Jumali MH, Salleh MM, Yahaya M. Characterization of multilayer graphene prepared from short-time processed graphite oxide flake. J Mater Sci. 2013;24(4):1282-6.

[33] Johra FT, Lee JW, Jung WG. Facile and safe graphene preparation on solution based platform. J Indus Eng Chem. 2014;20(5):2883-7.

[34] Mondal J, Marques A, Aarik L, Kozlova J, Simoes A, Sammelselg V. Development of a thin ceramic-graphene nanolaminate coating for corrosion protection of stainless steel. Corros Sci. 2016;105:161-9.

[35] Liu X, Xiong J, Lv Y, Zuo Y. Study on corrosion electrochemical behavior of several different coating systems by EIS. Prog Org Coat. 2009;64(4):497-503.

[36] Yu Z, Di H, Ma Y, Lv L, Pan Y, Zhang C, et al. Fabrication of graphene oxide-alumina hybrids to reinforce the anti-corrosion performance of composite epoxy coatings. Appl Surf Sci. 2015;351:986-96.

[37] Wei H, Ding D, Wei S, Guo Z. Anticorrosive conductive polyurethane multiwalled carbon nanotube nanocomposites. J Mater Chem A. 2013;1(36):10805-13.

[38] Li Z, Young RJ, Wang R, Yang F, Hao L, Jiao W, et al. The role of functional groups on graphene oxide in epoxy nanocomposites. Polymer. 2013;54(21):58219. 